\title{
College Students' Health Education and College Sports Environment
}

\author{
$\mathrm{Bin} \mathrm{Xu}$ \\ College of Foreign Languages, Northeast Dianli University, Jilin, 132012, China
}

\begin{abstract}
Health education and physical education environment are two significant factors that affect college students set up the correct health perspectives, enhance their health consciousness, have healthy behavior and life style. If the influence of sports environment is consistent with health education in direction and nature, it can strengthen the effect of health education, adversely, it can eliminate the effect of health education.
\end{abstract}

Keywords-health education, sports environment, college student

\section{INTRODUCTION}

During new century and new stage, the Party puts forward new requirements on college students' health education and deployment from the strategy of building a well-off society in an all-round way and the perspective of talent training the basic engineering, that is the establishment of school education guiding ideology "health first" and the implementation of the new PE course based on health, paying more attention to students' health and quality of life. College students' health education work, however, are facing many challenges, including school physical education environment is a factor which cannot be ignored.

\section{THE DEFINITION OF SPORTS ENVIRONMENT}

College sports environment includes the physical and social environment. It refers to the environment in the scope of this particular school, students through physical interaction with people around him and with characteristic of the school sports, sports culture, traditional showed interpersonal atmosphere in sports activities and sports task goal clarity, etc. Mainly by the historical tradition of the university sports itself, sports culture, management style, the atmosphere of the interpersonal relationship, etc. The pros and cons of this kind of environment impact on student health education, has very crucial role.

\section{INTERACTION BETWEEN PHYSICAL ENVIRONMENT AND HEALTH EDUCATION}

Health education is not only a theory process, but a practical process [1]. School sports environment provides students with the concrete practice health education environment both in sports teaching environment and sports living environment, its influence being directly, its role being more effectiveness and more closely. In the formation process of student's health awareness, attitude and health behavior and life style and the formation of a health education and campus sports environment is affecting the emergence, development and change of the external conditions. This is the health education and sports environment on the formation of the students' health awareness and attitude in common.

\section{A. The diversity multiplicity and variability characteristics of the current college students' sports environment become more prominent}

At present, college sports and health education is in a critical period of development change. New curriculum standard and the national ordinary higher school physical education curriculum teaching instruction summary the implementation of established the teaching idea of peopleoriented, and changed the combination of teaching and learning form, generating a variety of forms, rich in content of sports teaching environment. Sports socialization of colleges and universities, colleges and universities is changing the traditional form of sports exchanges, expand the sports cultural exchanges between the school and society, the more competitive, challenging, stimulating social sports content attracts students into the complicated and changeable social sports environment, apparent effects on students' body and mind.

\section{B. Under the complicated condition of the sports} environment, the health education of college students space is expanded

As the change of physical education concept and update, the school sports basic functions of the original physical education teaching, sports training and group activities can not meet the needs of social development and the students, the education function of sport and health, broke through the fence will spread and extension the school. The openness of the university sports environment, make the college sports environment and the wild natural environment and social environment to communicate, not only for college students in the school social life behavior, behavior way and the demand by the specification provides occasions, but also expanded the health education of college students. Make in constant contact with society, college students internalize health significance in the process, understand the social significance of health education and health promotion, to improve students' awareness of the body, life, health and sports, form the correct health perspectives.

\section{Strengthening the role of the environment posed a challenge to health education for college students}

Enhancement refers to the subjective understanding of external stimuli on human solidarity and deepen the process. Strengthening the role of the environment mainly 
in three aspects: first, the Pan-effect. In real life, people are exposed to the diversity of environments, each environmental factor is not as obvious as biological factors specific effects of many environmental factors have a large overlap. Second, the constancy and cumulative. Environment exists in people's real life, environment, dense and durable effect on humans, namely the permanency of the role. Third, the interaction. Environmental effects on the people by way of interactive on the one hand, text, images, sound, action and other forms of interaction.

\section{PHYSICAL ENVIRONMENT EDUCATION INTO FULL PLAY}

Health education for college students is of equal importance to the education enhancement. However, as a result of education limited in time, space, and the mental and physical development of college students, enhancement of health education strengthened more than the environment. This creates contrast between the effect of health education and environmental impact: in the face of increasingly rich sports changing environmental factors in the new era, students ' health education have been grappling with effective educational methods, but the results are not satisfactory; when the results of health education and the growing strength of physical environmental impacts after collision, the guiding role of health education will suffer. From the viewpoint of health education "Optimization" is not only the State of the physical environment are, more students interaction with the physical environment. So, "Optimization" is from the perspective of the relationship from both educators and education subject terms. Health education is to interact with the physical environment in the process of looking for a reasonable tension, makes the role education and physical environment promote each other. In other words, it means to play the role in education of the physical environment.

\section{A. Develop the guiding role of physical environment}

According to theory, the environment has a strong role. Good environmental conditions will promote the motivation to achieve and promote the formation of new behavior, consolidation and maintenance to ensure that various health risk factors that affect control [3]. Sports health-consciousness and behaviors of members within the school environment are formed and changed the soil. The correct guidance of public opinion is to strengthen the environmental orientation of the primary content. Any similar thing has its particularity, in particular traditions and characteristics, they are the Foundation of University development and prerequisites. Once the environment is formed of a college sports culture, awareness, attitudes, habits and behaviors of college students have a broad impact. Campus sports culture relies on and through college this carrier to reflect and spread various sports culture phenomenon, it is campus culture of a Asia culture, it of functions is through must of material environment and social environment makes life in which of each members are intentionally or unintentionally to in thought concept, and psychological factors, and behavior guidelines, and value orientation, aspects and reality culture occurred identity, thus achieved on shaping people of spirit, soul, and character.

\section{B. Make use of the incentive influence of the physical environment}

According to the view of psychology, human needs are the source of motivation, need to stimulate motivation, motivation, action point to the destination, purpose and new needs. Human behavior is caused by the need to force induced by a combination of tension and environment, Germany Lewin, a psychologist came from a combination of psychological theory, he believed that human behavior motivation comes from "Psycho". Possession or control which is inherent to the human motivations of the external environment, whether it's social, intellectual and physical. When people feel or when they attempt to control the external environment for success, you will feel your ability and emotional experience of inner joy, desire for possession or control the coming of the next task. When it is in possession or control of a choice and through their own efforts to complete the task, a more pleasant feelings [4] Convince college students in thinking that "I can", "I can" on the behavior performance, in the emotional experience, "I can" good campus physical environment for each student to create and provide equal experience "I can" chance, is to train students' correct health consciousness, forming a positive attitude to health, develop an effective way to consciously adhere to the healthy behavior and way of life.

\section{Pay attention to the normative role of physical environment}

Environment of guide and specification are mutually unified, in a sense, specification is the boot. In comparison, the specification is mandatory. Based on the characteristics of the sports environment specification function, one is to strengthen management, giving full play to its specification system. Secondly, elaborate organization, bring into play the function of sports culture itself has a specification. Strengthen management, improve the system environment construction is the foundation of the play a role of environmental specification. System is to achieve not by means of a conscious level, is in order to ensure the school health education has a chapter, orderly and effective. Purpose is to use system to strengthen the first, and then use situation to internalization. Successful experience at home and abroad has confirmed that a strong, targeted policy and the relevant rules and regulations will effectively promote the behavior change and can effectively maintain the behavior [3]. From the point of the effect of health education, there is no good system environment as the foundation, the lack of health education

An orderly sports environment as a condition of support. College sports have strong direct participation, fierce competition and frequent interpersonal 
communication, as well as the contents of various activities, the place that it provides social norms education to college students and practice social norms simulation opportunities [5]. Campus sports culture in the principle of "Olympic", "the rules of the contest" and "Olympic spirit", "sports ethics" ", athletes style "and so on all affect individual in the environment, they can fully feel the" law ", the code of ethics "of social significance. Internalization process of this kind of "social norms", to help college students from their obligations, rights and responsibilities, coordinate the relationship between individuals, groups, society, set up the self and group health consciousness, forming scientific and healthy behavior and way of life.

\section{CONCLUSIONS}

In contemporary colleges and universities, strengthening and improving University student's health education must pay attention to physical changes in the environment, and we cannot ignore the influence of sports environment on students ' health education. The positive way to response this is the initiative to create and make full use of the physical environment.

\section{CORRESPONDING AUTHOR}

Bin $\mathrm{Xu}$. College of Foreign Languages, Northeast Dian li University, Jilin, 132012, China.

Email:34063479@qq.com.TEL:15843294007

\section{REFERENCES}

[1] Jiangyi, Li Xiaofeng. China needs health education: and the comprehensive view of health education[J]. Journal of Chengdu Institute of physical education, 2001, 27(2): 42- 44.

[2] Lu Wenyu, Sun Bairen. Introduction to health education for college students[M]. Beijing: Economic science press, 2002(8): 2- 3.

[3] Yang Zhongwei. Sports and health promotion [M] Beijing: Higher education press, 2004(6): 58- 61.

[4] Wang Gaohua. Physical education new course design [M] Beijing: Higher education press2003(8): 96- 100.

[5] Wu Yonghui. College physical education and the socialization of college students[J] Adult education, 2005(7):73- 74 